\title{
Patient characteristics of smokers undergoing lumbar spine surgery: an analysis from the Quality Outcomes Database
}

\author{
Anthony L. Asher, MD, ${ }^{1}$ Clinton J. Devin, MD, ${ }^{2}$ Brandon McCutcheon, MD, ${ }^{3}$ Silky Chotai, MD, ${ }^{2}$ \\ Kristin R. Archer, PhD, ${ }^{4,5}$ Hui Nian, PhD, ${ }^{6}$ Frank E. Harrell Jr., PhD, ${ }^{6}$ Matthew McGirt, MD, ${ }^{1}$ \\ Praveen V. Mummaneni, MD, ${ }^{7}$ Christopher I. Shaffrey, MD, ${ }^{8}$ Kevin Foley, MD, ${ }^{9}$ \\ Steven D. Glassman, MD, ${ }^{10}$ and Mohamad Bydon, MD, ${ }^{3}$ for the QOD Vanguard Sites
}

\begin{abstract}
'Department of Neurological Surgery, Carolina Neurosurgery and Spine Associates and Neuroscience Institute, Carolinas Healthcare System, Charlotte, North Carolina; 'Departments of Orthopaedic Surgery and Neurological Surgery, Vanderbilt Spine Center, Vanderbilt University Medical Center, Nashville, Tennessee; ' ${ }^{D}$ Department of Neurosurgery, Mayo Clinic, Rochester, Minnesota; Departments of ${ }^{4}$ Orthopaedic Surgery, Vanderbilt Spine Center, ${ }^{5}$ Physical Medicine and Rehabilitation, and ${ }^{6}$ Biostatistics, Vanderbilt University School of Medicine, Nashville, Tennessee; ${ }^{7}$ Department of Neurological Surgery, University of California, San Francisco, California; ${ }^{8}$ Department of Neurosurgery, University of Virginia Medical Center, Charlottesville, Virginia; ' ${ }^{D}$ epartment of Neurosurgery, University of Tennessee Health Sciences Center, Semmes Murphey Neurologic and Spine Institute, Memphis, Tennessee; and ${ }^{10}$ Department of Orthopedic Surgery, University of Louisville, and the Norton Leatherman Spine Center, Louisville, Kentucky
\end{abstract}

OBJECTIVE In this analysis the authors compare the characteristics of smokers to nonsmokers using demographic, socioeconomic, and comorbidity variables. They also investigate which of these characteristics are most strongly associated with smoking status. Finally, the authors investigate whether the association between known patient risk factors and disability outcome is differentially modified by patient smoking status for those who have undergone surgery for lumbar degeneration.

METHODS A total of 7547 patients undergoing degenerative lumbar surgery were entered into a prospective multicenter registry (Quality Outcomes Database [QOD]). A retrospective analysis of the prospectively collected data was conducted. Patients were dichotomized as smokers (current smokers) and nonsmokers. Multivariable logistic regression analysis fitted for patient smoking status and subsequent measurement of variable importance was performed to identify the strongest patient characteristics associated with smoking status. Multivariable linear regression models fitted for 12-month Oswestry Disability Index (ODI) scores in subsets of smokers and nonsmokers was performed to investigate whether differential effects of risk factors by smoking status might be present.

RESULTS In total, $18 \%(n=1365)$ of patients were smokers and $82 \%(n=6182)$ were nonsmokers. In a multivariable logistic regression analysis, the factors significantly associated with patients' smoking status were sex $(p<0.0001)$, age $(p<0.0001)$, body mass index ( $<<0.0001)$, educational status $(p<0.0001)$, insurance status $(p<0.001)$, and employment/occupation $(p=0.0024)$. Patients with diabetes had lowers odds of being a smoker $(p=0.0008)$, while patients with coronary artery disease had greater odds of being a smoker $(p=0.044)$. Patients' propensity for smoking was also significantly associated with higher American Society of Anesthesiologists (ASA) class $(p<0.0001)$, anterior-alone surgical approach $(p=0.018)$, greater number of levels $(p=0.0246)$, decompression only $(p=0.0001)$, and higher baseline ODI score $(p<0.0001)$. In a multivariable proportional odds logistic regression model, the adjusted odds ratio of risk factors and direction of improvement in 12-month ODI scores remained similar between the subsets of smokers and nonsmokers. CONCLUSIONS Using a large, national, multiinstitutional registry, the authors described the profile of patients who undergo lumbar spine surgery and its association with their smoking status. Compared with nonsmokers, smokers

ABBREVIATIONS ASA = American Society of Anesthesiologists; $B M I=$ body mass index; BP = back pain; CAD = coronary artery disease; LP = leg pain; NRS = numeric rating scale; $\mathrm{ODI}=$ Oswestry Disability Index; OR = odds ratio; $P R O=$ patient-reported outcome; $Q O D=$ Quality Outcomes Database.

SUBMITTED August 19, 2016. ACCEPTED April 10, 2017.

INCLUDE WHEN CITING Published online September 29, 2017; DOI: 10.3171/2017.4.SPINE16984. 
were younger, male, nondiabetic, nonobese patients presenting with leg pain more so than back pain, with higher ASA classes, higher disability, less education, more likely to be unemployed, and with Medicaid/uninsured insurance status. Smoking status did not affect the association between these risk factors and 12-month ODI outcome, suggesting that interventions for modifiable risk factors are equally efficacious between smokers and nonsmokers.

https://thejns.org/doi/abs/10.3171/2017.4.SPINE16984

KEY WORDS QOD; patient-reported outcomes; smoking; lumbar; surgery

$\mathrm{I}$ $\mathrm{N}$ the modern era, data scientists are able to amass ever-larger quantities of clinically relevant data at rapidly increasing rates. The Quality Outcomes Database (QOD), formerly known as the National Neurosurgery Quality and Outcomes Database ( $\left.\mathrm{N}^{2} \mathrm{QOD}\right)$, is a manifestation of this trend..$^{2,24}$ While administrative data sets historically provided researchers with large sample sizes, they often lacked important clinical information. Conversely, at their individual institutions, researchers had the power to generate highly granular clinical data but at the cost of a reduced sample size and, thus, statistical power. The QOD, in contrast, offers the benefits of both paradigms and allows spine surgeons to gain new insight into critical clinical topics.

There is extensive literature documenting that patient smoking status is strongly associated with worse outcomes following spine surgery. One study found that rates of readmission, need for intensive care unit admission, length of stay, and total cost following spine surgery were increased for smokers relative to nonsmokers. ${ }^{4}$ A separate study demonstrated higher rates of reoperation among smokers receiving a single- or multiple-level laminectomy. ${ }^{6}$ Similar results have also been noted for minimally invasive spine surgery. Gulati et al. reported decreased improvement in patient Oswestry Disability Index (ODI) scores at 1 year among smokers relative to nonsmokers following microdecompression for lumbar spinal stenosis. ${ }^{12}$ A separate study noted a 2 -fold increased risk of deterioration of patient ODI scores for smokers receiving decompression for lumbar spinal stenosis. ${ }^{28}$ Therefore, the impact of patient smoking status on outcomes has been previously quantified. ${ }^{4-6,12,13,15,17,18,21,23,26,27,30-34}$ However, the question remains: compared with nonsmokers, what characteristics of smokers contribute to the less desirable outcomes after spine surgery?

In this analysis, we compare the clinical characteristics of smokers with those of nonsmokers among patients undergoing degenerative lumbar surgery and included in the QOD data set. Our study aims were: 1) to determine the characteristics of the smokers, and 2) to investigate the effect of risk factors for 12-month patient-reported outcomes (PROs) on smokers and nonsmokers.

\section{Methods \\ Data Source}

Patients undergoing elective spine surgery for degenerative lumbar disease were entered into the prospective multicenter QOD registry over a 2-year period. The QOD is a prospective observational registry designed to collect measures of surgical safety and PROs at 12 months af- ter surgery and establish risk-adjusted expected morbidity. The overall goal is to improve efficiency and quality of care for the most common lumbar surgical procedures performed by spine surgeons. The QOD registry enrolls spine surgery patients from 74 participating centers across 28 US states via representative sampling. ${ }^{2,24}$ Baseline and yearly postoperative pain, disability, and quality of life scores were assessed via self-administration or phone interview by an independent data coordinator not involved with clinical care. Data were collected through a secure password-protected Web-based portal (Research Electronic Data Capture, or REDCap) into a national aggregate database.${ }^{16}$ For this study, a retrospective analysis of the prospectively collected data was conducted.

\section{Inclusion and Exclusion Criteria}

Patients undergoing lumbar surgery performed for primary stenosis, spondylolisthesis, disc herniation, symptomatic mechanical disc collapse, and revision surgery, including recurrent same-level disc herniation and adjacent-segment disease, who had at least 12 months of follow-up, were eligible for inclusion. Exclusions included spinal infection, tumor, fracture, traumatic dislocation, deformity, pseudoarthrosis, same-level recurrent multilevel stenosis, pseudarthrosis, same-level recurrent multilevel stenosis, neurological paralysis due to preexisting spinal disease or injury, less than 18 years of age, incarceration, unavailable information regarding ODI scores at baseline and 12 months postoperatively, and unavailable data on smoking status.

\section{Outcome Measures}

The primary outcome of interest was 12-month postoperative ODI score. ${ }^{9}$ Secondary measures were assessed using validated questionnaires and included: 1) pain, using the numeric rating scale (NRS) for back pain (NRS-BP) and leg pain (NRS-LP); ${ }^{20}$ and 2) preference-based health status, using the EQ-5D?

\section{Statistical Analysis}

Mean, standard deviation, quartiles for continuous variables, and frequencies for categorical variables were calculated for patient demographics. Bivariate analyses were conducted using the Mann-Whitney U-test for continuous data and chi-square test for nominal data. Patients were dichotomized as smokers (current smokers) and nonsmokers.

A multivariable logistic regression model was fitted for smoking status (yes or no). The odds of being a smoker were calculated with respect to patient demographic and 


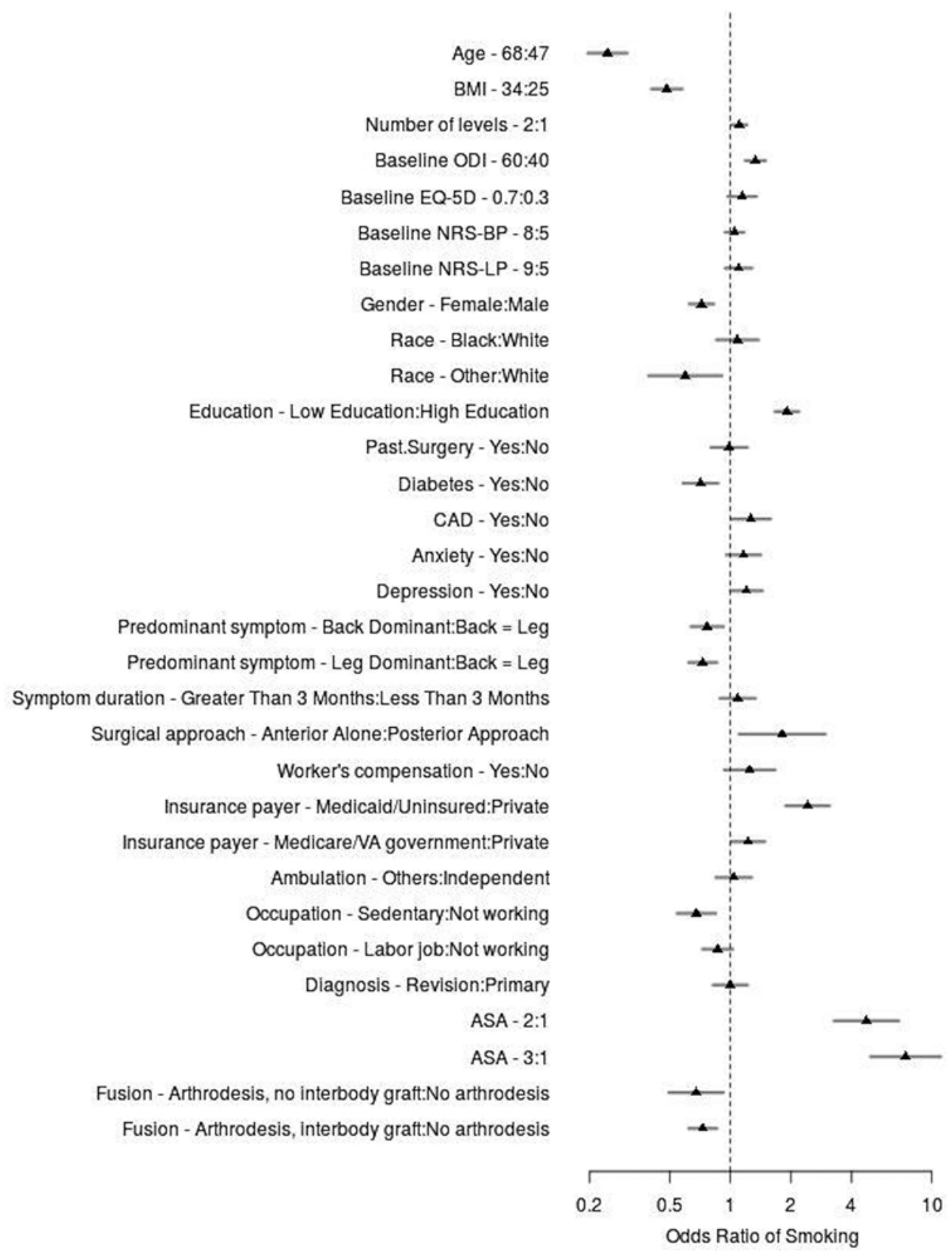

FIG. 1. Adjusted effects of variables on smoking status, demonstrating the odds of being a smoker. VA = Veterans Affairs.

comorbidity data (Fig. 1). The independent variables included in the model are listed in Table 1 and demonstrated in Fig. 1. For continuous variables, odds ratios (ORs) were calculated comparing the 75 th percentile to the 25 th percentile. The association between other risk factors and patient smoking status was computed using the following formula: Wald chi-square value minus predictor degree of freedom (Fig. 2). The higher the difference, the higher is the importance of that predictor for patient smoking status. To investigate whether the effect of patient risk factors on 12-month ODI outcome is associated with patient smoking, we fitted separate multivariable proportional odds ordinal logistic regression models (Fig. 3) in subsets of smokers and nonsmokers. Two-sided $\mathrm{p}$ values less than
0.05 were considered statistically significant. The analysis was performed using the $\mathrm{R}$ statistical program (version 3.1.2, www.R-project.org). ${ }^{14}$

\section{Results}

A total of 7547 patients undergoing degenerative lumbar surgery with 12 months of follow-up were analyzed. In total, $18 \%(\mathrm{n}=1365)$ of patients were smokers and $82 \%(\mathrm{n}$ $=6182$ ) were nonsmokers. Table 1 demonstrates the patient baseline characteristics, diagnosis, and surgery-specific variables in smokers and nonsmokers.

\section{Characteristics of Smokers}

In a multivariable logistic regression analysis, the fac- 
TABLE 1. Phenotypic characteristics of smokers compared with nonsmokers

\begin{tabular}{|c|c|c|c|c|}
\hline Variable & Total & $\begin{array}{c}\text { Smokers } \\
(\%)\end{array}$ & $\begin{array}{c}\text { Nonsmokers } \\
(\%)\end{array}$ & $\begin{array}{c}p \\
\text { Value }\end{array}$ \\
\hline No. of patients & 7547 & 1365 & 6182 & \\
\hline Mean age $\pm S D$ (yrs) & 7532 & $52 \pm 13$ & $60 \pm 14$ & $<0.001$ \\
\hline Sex & 7544 & & & 0.019 \\
\hline Male & & $745(55)$ & $3155(51)$ & \\
\hline Female & & $620(45)$ & 3024 (49) & \\
\hline Mean BMI \pm SD & 7528 & $29.5 \pm 6.2$ & $30.5 \pm 6.9$ & $<0.001$ \\
\hline Race & 7547 & & & $<0.001$ \\
\hline White & & $1202(88)$ & $5634(91)$ & \\
\hline Black & & $131(10)$ & $368(6)$ & \\
\hline Other & & $32(2)$ & $180(3)$ & \\
\hline Education & 7490 & & & $<0.001$ \\
\hline Low education & & $856(63)$ & $2709(44)$ & \\
\hline High education & & $504(37)$ & $3421(56)$ & \\
\hline Occupation & 7518 & & & $<0.001$ \\
\hline Sedentary & & $159(12)$ & $1040(17)$ & \\
\hline Labor job & & $493(36)$ & $1831(30)$ & \\
\hline Not working & & $708(52)$ & $3287(53)$ & \\
\hline Compensation & & $87(6)$ & $198(3)$ & $<0.001$ \\
\hline Insurance & 7530 & & & \\
\hline Medicaid/uninsured & & $198(15)$ & $200(3)$ & \\
\hline $\begin{array}{l}\text { Medicare/VA gov- } \\
\text { ernment }\end{array}$ & & $363(27)$ & $2565(42)$ & \\
\hline Private & & $798(59)$ & $3406(55)$ & \\
\hline Anxiety & 7532 & $307(22)$ & 860 (14) & $<0.001$ \\
\hline Depression & 7535 & $385(28)$ & $1161(19)$ & $<0.001$ \\
\hline Diabetes & 7546 & $174(13)$ & $1098(18)$ & $<0.001$ \\
\hline CAD & 7533 & $145(11)$ & $716(12)$ & 0.32 \\
\hline Prior surgery & 7540 & $158(12)$ & $638(10)$ & 0.18 \\
\hline Dominant symptom & 7547 & & & $<0.001$ \\
\hline Back \& leg equal & & $727(53)$ & $2653(43)$ & \\
\hline Back dominant & & $260(19)$ & $1263(20)$ & \\
\hline Leg dominant & & $378(28)$ & $2266(37)$ & \\
\hline Symptom duration & 7487 & & & 0.93 \\
\hline$>3 \mathrm{mos}$ & & $1188(88)$ & $5391(88)$ & \\
\hline$<3$ mos & & $165(12)$ & $743(12)$ & \\
\hline Ambulation & 6924 & & & 0.078 \\
\hline Independent & & $1039(84)$ & $4487(85)$ & \\
\hline Others & & $198(16)$ & $800(15)$ & \\
\hline Diagnosis & 7544 & & & 0.004 \\
\hline Primary & & $1176(86)$ & $5493(89)$ & \\
\hline Revision & & $189(14)$ & $686(11)$ & \\
\hline Approach & 7334 & & & $<0.001$ \\
\hline Posterior & & $1284(97)$ & $5916(98)$ & \\
\hline Anterior & & $40(3)$ & $94(2)$ & \\
\hline Surgical levels & 7133 & & & 0.1 \\
\hline 1 & & $517(40)$ & $2283(39)$ & \\
\hline 2 & & $567(44)$ & $2496(43)$ & \\
\hline
\end{tabular}

CONTINUED IN NEXT COLUMN »
》 CONTINUED FROM PREVIOUS COLUMN

TABLE 1. Phenotypic characteristics of smokers compared with nonsmokers

\begin{tabular}{lcccc}
\hline \multicolumn{1}{c}{ Variable } & Total & $\begin{array}{c}\text { Smokers } \\
(\%)\end{array}$ & $\begin{array}{c}\text { Nonsmokers } \\
(\%)\end{array}$ & $\begin{array}{c}p \\
\text { Value }\end{array}$ \\
\hline $\begin{array}{c}\text { Surgical levels } \\
\text { (continued) }\end{array}$ & 7133 & & 0.1 \\
\hline 3 & & $163(13)$ & $839(14)$ & \\
\hline 4 & & $37(3)$ & $231(4)$ & \\
\hline Arthrodesis & 7484 & $441(32)$ & $2218(36)$ & 0.41 \\
\hline Interbody graft & 7363 & $348(25)$ & $1776(29)$ & 0.68 \\
\hline ASA class & 7472 & & & $<0.001$ \\
\hline I & & $37(3)$ & $460(7)$ & \\
\hline II & & $803(59)$ & $3374(55)$ & \\
\hline III & $511(38)$ & $2287(37)$ & \\
\hline
\end{tabular}

$\mathrm{VA}=$ Veterans Affairs.

tors associated with patient smoking status were analyzed in a risk-adjusted fashion (Fig. 1). Patient smoking status was significantly associated with age (younger age: $\mathrm{p}<$ 0.0001 ), sex (male: $\mathrm{p}<0.0001)$, body mass index (BMI) ( $\mathrm{p}<0.0001$ ), educational status (low education level: $\mathrm{p}$ $<0.0001$ ), insurance status (Medicaid/uninsured: $\mathrm{p}<$ 0.001 ), and employment/occupation (sedentary type of occupation: $\mathrm{p}=0.0024)$. Patients presenting with dominant LP had higher odds of being a smoker $(p=0.0001)$. Patients with diabetes had lower odds of being a smoker $(\mathrm{p}=0.0008)$, while patients with coronary artery disease (CAD) had higher odds of being a smoker $(\mathrm{p}=0.044)$. Patients' propensity for smoking was also significantly associated with higher classification according to the Physical Status Classification System of the American Society of Anesthesiologists (ASA) ( $<<0.0001)$, an anterior-alone surgical approach $(\mathrm{p}=0.018)$, greater number of levels $(\mathrm{p}$ $=0.0246)$, decompression only $(\mathrm{p}=0.0001)$, as well as higher baseline ODI score $(\mathrm{p}<0.0001)$. Figure 2 displays the adjusted and unadjusted importance of each variable included in the multivariable model. The variables that had the greatest association with smoking status were patient age, BMI, ASA classification, education, and insurance status.

\section{Outcomes}

All patients demonstrated a significant improvement in ODI, NRS-LP, NRS-BP, and EQ-5D scores ( $\mathrm{p}<0.001)$. The smokers had significantly worse 12-month ODI scores $(31 \pm 24$ vs $22 \pm 20, \mathrm{p}<0.001)$, NRS-BP $(4.1 \pm 3.2$ vs $2.9 \pm 2.9, \mathrm{p}<0.001), \mathrm{NRS}-\mathrm{LP}(3.4 \pm 3.4$ vs $2.3 \pm 2.9$, p $<0.001)$, and EQ-5D (0.70 \pm 0.25 vs $0.79 \pm 0.20, \mathrm{p}<0.001)$ compared with nonsmokers (Table 2).

\section{Effect Modification of Risk Factors on 12-Month Outcomes}

In a multivariable proportional odds logistic regression model, to evaluate the effect of smoking on the risk factors associated with worse 12-month ODI outcome, the adjusted OR of risk factors and direction of improvement 


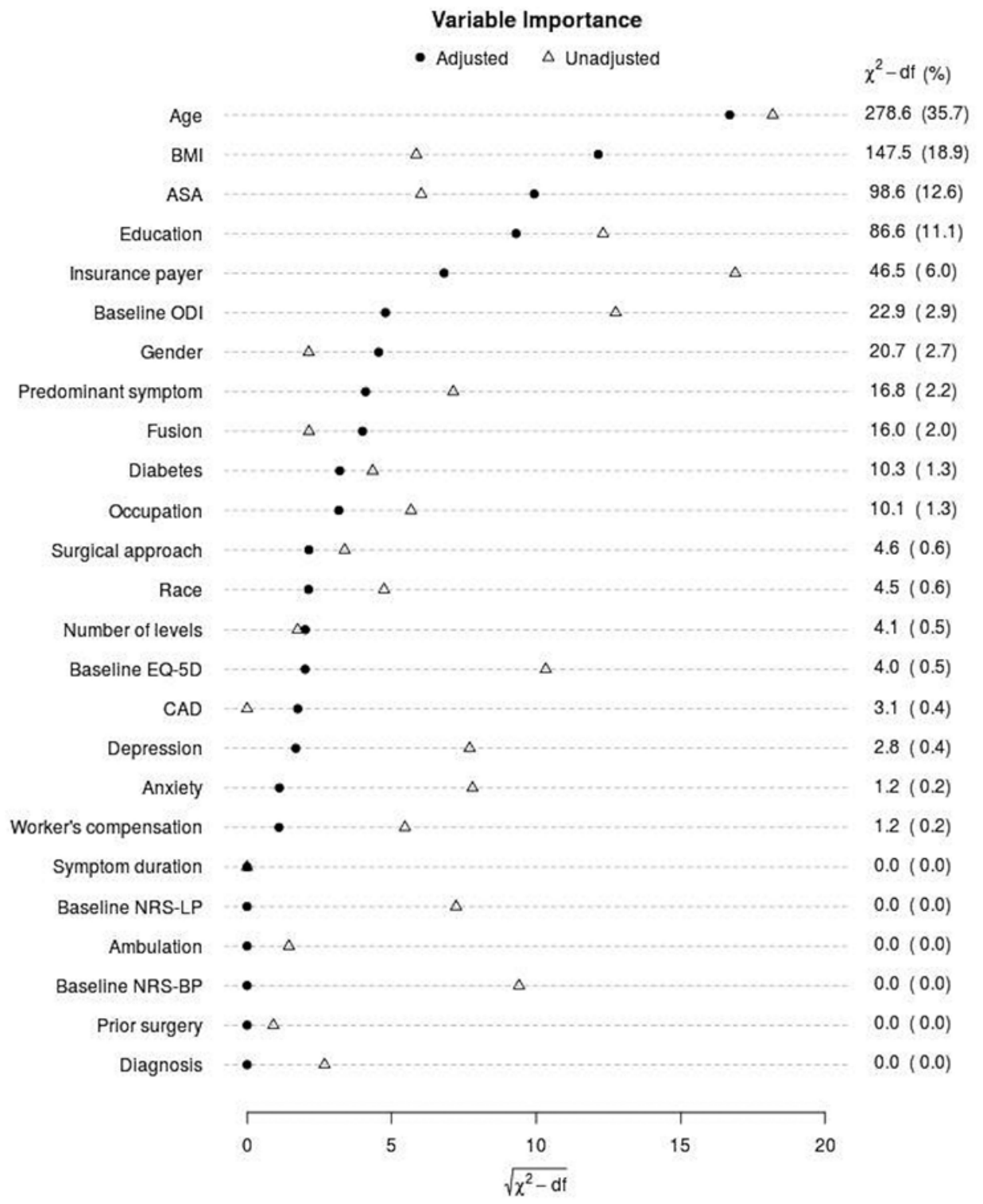

FIG. 2. Predictor importance for association of baseline characteristics with smoking status.

in 12-month ODI scores remained similar between the subsets of smokers and nonsmokers (Fig. 3). Similarly, the adjusted OR of risk factors and direction of improvement in 12-month NRS-BP, NRS-LP, and EQ-5D outcomes were similar between smokers and nonsmokers (Supplemental Figs. 1-3).

\section{Discussion}

This study uses prospectively collected data from the QOD registry to investigate differences in patient characteristics between smokers and nonsmokers undergoing surgery for degenerative lumbar disease. We found that smokers were significantly different from nonsmokers with regard to demographic characteristics, socioeconomic measures, comorbidities, and baseline PROs. Smokers were more likely to be younger, male, nondiabetic, nonobese, presenting with dominant LP, to have a higher ASA class, greater disability, less education, less likelihood to be employed, and a Medicaid/uninsured insurance status. In terms of surgical variables, the smokers were less likely to undergo fusion surgery, and for those undergoing fusion, the smokers had a higher number of levels involved compared with nonsmokers. Despite these differences, the adjusted OR of factors associated with outcomes and the direction of improvement in 12-month ODI scores remained similar between the subsets of smokers and nonsmokers.

Understanding the characteristics of smokers can be useful for clinicians evaluating patients with a history of smoking to recognize that they are associated with a unique profile of demographic, socioeconomic, and comorbidity characteristics that are fundamentally different from their nonsmoking counterparts. While clinicians should consider the biological effects of smoking on postoperative healing and functional outcomes, this study may motivate clinicians to additionally consider the broader 
A. L. Asher et al.

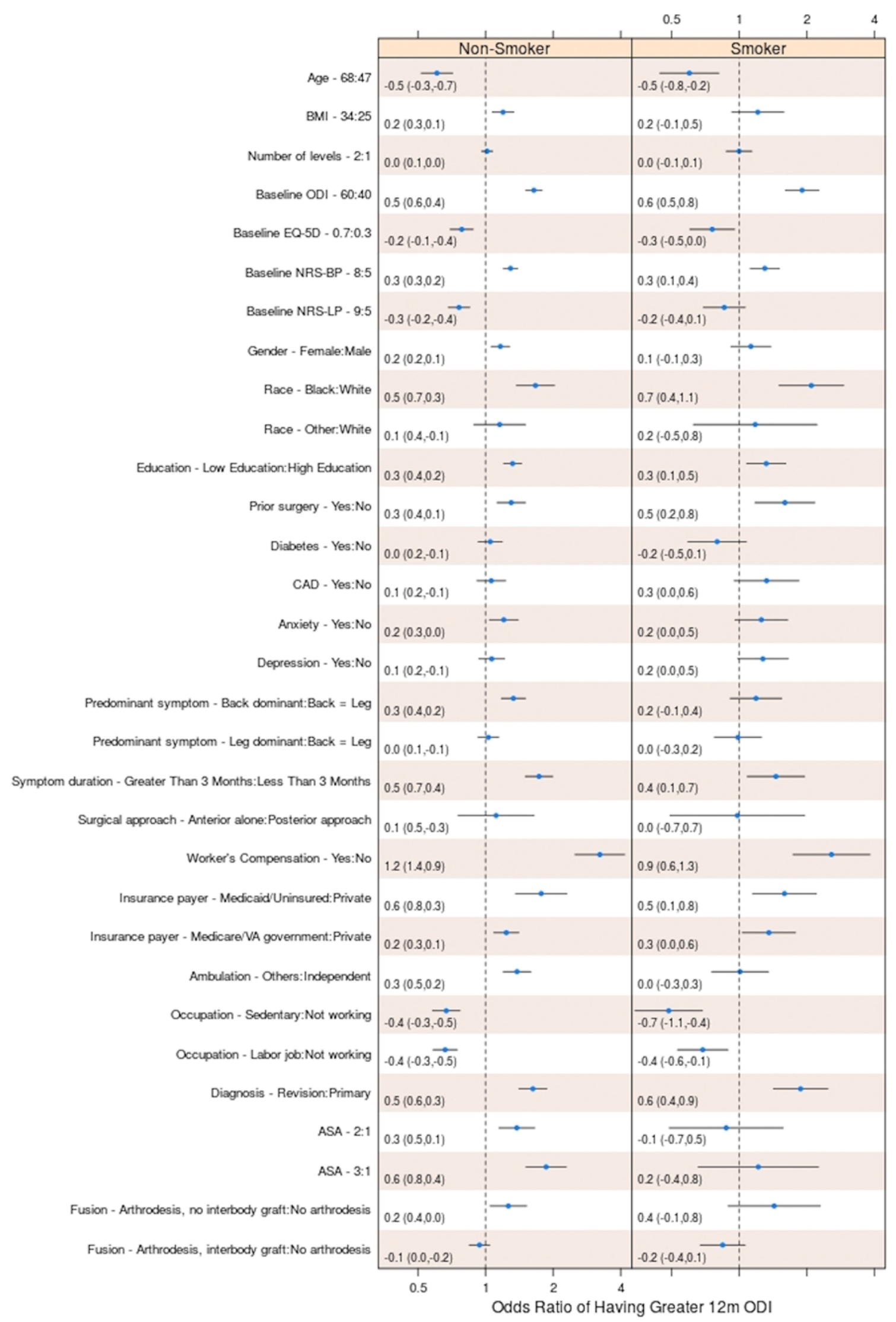

FIG. 3. Adjusted effect of variables on 12-month (12m) ODI scores for smokers and nonsmokers. Figure is available in color online only. 
TABLE 2. Baseline PROs, 12-month PROs, and change in scores from baseline to 12 months postoperatively for smokers and nonsmokers

\begin{tabular}{ccccc}
\hline \multicolumn{1}{c}{ PROs } & Total & Smokers (\%) & Nonsmokers (\%) & p Value \\
\hline Baseline PROs & & & & \\
\hline ODI & 7545 & $54 \pm 16$ & $47 \pm 17$ & $<0.001$ \\
\hline NRS-BP & 7537 & $7.1 \pm 2.5$ & $6.3 \pm 2.8$ & $<0.001$ \\
\hline NRS-LP & 7539 & $7.4 \pm 2.4$ & $6.8 \pm 2.7$ & $<0.001$ \\
\hline EQ-5D & 7504 & $0.49 \pm 0.22$ & $0.56 \pm 0.22$ & $<0.001$ \\
\hline 12-mo PROs & & & & \\
\hline ODI & 7545 & $31 \pm 24$ & $22 \pm 20$ & $<0.001$ \\
\hline NRS-BP & 7537 & $4.1 \pm 3.2$ & $2.9 \pm 2.9$ & $<0.001$ \\
\hline NRS-LP & 7539 & $3.4 \pm 3.4$ & $2.3 \pm 2.9$ & $<0.001$ \\
\hline EQ-5D & 7547 & $0.70 \pm 0.25$ & $0.79 \pm 0.20$ & $<0.001$ \\
\hline Change in score & & & & \\
PROs & & & & \\
\hline ODI & 7545 & $23 \pm 22$ & $25 \pm 20$ & $<0.001$ \\
\hline NRS-BP & 7537 & $3.0 \pm 3.3$ & $3.4 \pm 3.3$ & $<0.001$ \\
\hline NRS-LP & 7539 & $3.0 \pm 3.3$ & $4.4 \pm 3.6$ & $<0.001$ \\
\hline EQ-5D & 7547 & $0.21 \pm 0.27$ & $0.24 \pm 0.24$ & 0.002 \\
\hline
\end{tabular}

Data for the smoking and nonsmoking groups given as mean percentages \pm SDs.

milieu of comorbidities and other preoperative characteristics that will influence postoperative outcomes for patients who smoke. Therefore, in addition to counseling patients regarding smoking cessation, it is vital to understand that other interventions might be needed in this population to achieve better outcomes. For instance, prior studies have demonstrated that a higher education level might allow for better understanding of the disease process compared with patients with lower education levels. ${ }^{19,29}$ In our analysis, the smokers had lower education levels compared with nonsmokers; therefore, providing additional counseling on the disease process would allow these patients to have realistic postoperative expectations, making them more treatment compliant, and ultimately resulting in better postoperative recovery.

Previous studies have demonstrated that socioeconomic factors including lower levels of education, unemployment, workers' compensation, and disability insurance were associated with poor outcomes following spine surgery. ${ }^{1,3,8}$, $10,11,25$ Some of these factors characterized smokers in our study. Furthermore, consistent with other studies, our previous analysis has demonstrated that being a smoker is associated with poor disability outcomes following lumbar spine surgery. ${ }^{3-5,9,11,15,17,18,21-23,25,26,32-34}$ Therefore, it made sense to evaluate if being a smoker would have any effect on the previously described risk factors associated with poor outcomes. On comparing the adjusted OR of the risk factors for the 12-month disability (ODI) outcome, we found that all the risk factors were similarly associated with outcomes in both smokers and nonsmokers. This suggests that higher BMI, lower education status, unemployment, higher ASA classification, higher number of levels operated on, history of diabetes, and history of CAD results in worse outcomes in both smokers and nonsmokers.
Therefore, the strategies on the interventions addressing the modifiable risk factors for disability outcomes could be equally efficacious in smokers and nonsmokers.

This study has several inherent limitations. First, it is limited by the absence of detailed clinical imaging. As a result, this study cannot perform risk adjustment based on radiographic findings, which may be useful in assessing patient disease severity. Furthermore, the inclusion of multiple degenerative pathologies might introduce some heterogeneity and associated bias. While risk adjustment was robust, there may be unobserved confounders that cannot be accounted for in this study. The long-term complications or reoperations are not captured in this registry. This is particularly relevant as smoking may affect the durability of both fusion and nonfusion procedures, which may affect observed outcomes over a longer study period. Another limitation of this study was the lack of followup imaging data. The smokers may have higher rates of pseudarthrosis, which could affect the observed outcomes. A number of previous studies have demonstrated the association of smoking status with nonfusion and poor functional outcomes. ${ }^{4-6,12,13,15,17,18,21,23,26,27,30-33,35}$ The goal of this study was to determine the characteristics of smokers and to evaluate the effect of other risk factors for 12-month PROs on smokers and nonsmokers. The QOD registry does not capture detailed data on the intensity of tobacco use; therefore, a dose-quantity relationship of smoking to outcomes cannot be established.

This study demonstrates the strengths of a "big data" approach to clinical research. The QOD national project includes a diverse network of health care institutions and patient types, which allows for a true representative sampling of patients undergoing elective lumbar spine surgery. Furthermore, this is the first study to characterize smokers undergoing surgery for lumbar degenerative pathologies and to determine if smoking status has any impact on the other risk factors associated with PROs.

\section{Conclusions}

Using a large, national, multiinstitutional registry, we described the profile of patients who undergo lumbar spine surgery in association with their smoking status. Compared with nonsmokers, smokers were younger, male, nondiabetic, nonobese patients, presenting with LP more so than BP, had higher ASA classification, greater disability, were less educated, more likely to be unemployed, and had Medicaid/uninsured insurance status. The smoking status did not affect the association between these risk factors and 12-month ODI outcome, suggesting that interventions for modifiable risk factors are equally efficacious between smokers and nonsmokers.

\section{Acknowledgments}

A portion of this work was supported by a grant from the Neurosurgery Research and Education Foundation (NREF).

\section{Appendix QOD Vanguard Sites}

Anthony L. Asher, MD, ${ }^{1}$ Matthew J. McGirt, MD, ${ }^{1}$ Clinton J. 
Devin, MD, ${ }^{2}$ Joseph S. Cheng, MD, ${ }^{2}$ Kevin T. Foley, MD, ${ }^{3}$ Jeffrey M. Sorenson, MD, ${ }^{3}$ John J. Knightly, MD, ${ }^{4}$ Steven D. Glassman, MD, ${ }^{5}$ Thomas B. Briggs, MD, ${ }^{6}$ Adam Kremer, MD, ${ }^{7}$ Wesley E. Griffitt, MD ${ }^{8}$ Noam Y. Stadlan, MD, ${ }^{9}$ Thomas W. Grahm, MD, ${ }^{10}$ Meic H. Schmidt, MD, ${ }^{11}$ Praveen V. Mummaneni, MD,${ }^{12}$ and Mark E. Shaffrey, MD. ${ }^{13}$

${ }^{1}$ Department of Neurological Surgery, Carolina Neurosurgery and Spine Associates and Neuroscience Institute, Carolinas Healthcare System, Charlotte, North Carolina; ${ }^{2}$ Departments of Orthopaedic Surgery and Neurosurgery, Vanderbilt Spine Center, Vanderbilt University Medical Center, Nashville, Tennessee; ${ }^{3}$ Department of Neurosurgery, University of Tennessee Health Sciences Center, Semmes Murphey Neurologic and Spine Institute, Memphis, Tennessee; ${ }^{4}$ Department of Neurosurgery, Atlantic Neurosurgical Specialists, Morristown, New Jersey; ${ }^{5}$ Department of Orthopedic Surgery, University of Louisville, and the Norton Leatherman Spine Center, Louisville, Kentucky; ${ }^{6}$ Springfield Neurologic and Spine Institute, Springfield, Missouri; ${ }^{7}$ Department of Neurosurgery, Brain and Spine Center, Holland, Michigan; ${ }^{8}$ Department of Neurosurgery, Bay Care Clinic Neurological,

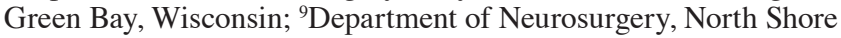
University Health System, Skokie, Illinois; ${ }^{10}$ Department of Surgery, East Texas Medical Center, Tyler Neurosurgical, Tyler, Texas; ${ }^{11}$ Department of Neurosurgery, University of Utah, Salt Lake City, Utah; ${ }^{12}$ Department of Neurological Surgery, University of California, San Francisco, California; and ${ }^{13}$ Department of Neurosurgery, University of Virginia Medical Center, Charlottesville, Virginia.

\section{References}

1. Anderson PA, Schwaegler PE, Cizek D, Leverson G: Work status as a predictor of surgical outcome of discogenic low back pain. Spine (Phila Pa 1976) 31:2510-2515, 2006

2. Asher AL, McCormick PC, Selden NR, Ghogawala Z, McGirt MJ: The National Neurosurgery Quality and Outcomes Database and NeuroPoint Alliance: rationale, development, and implementation. Neurosurg Focus 34(1):E2, 2013

3. Asher AL, McGirt M, Parker S, Mummaneni P, Glassman S, Knightly J, et al: Improvement in pain, disability, and quality of life following lumbar spine surgery: a predictive model from the $\mathrm{N}^{2} \mathrm{QOD}$ registry. J Neurosurg 123:A494-A495, 2015

4. Bisson EF, Bowers CA, Hohmann SF, Schmidt MH: Smoking is associated with poorer quality-based outcomes in patients hospitalized with spinal disease. Front Surg 2:20, 2015

5. Bydon M, De la Garza-Ramos R, Abt NB, Gokaslan ZL, Wolinsky JP, Sciubba DM, et al: Impact of smoking on complication and pseudarthrosis rates after single- and 2-level posterolateral fusion of the lumbar spine. Spine (Phila Pa 1976) 39:1765-1770, 2014

6. Bydon M, Macki M, De la Garza-Ramos R, Sciubba DM, Wolinsky JP, Gokaslan ZL, et al: Smoking as an independent predictor of reoperation after lumbar laminectomy: a study of 500 cases. J Neurosurg Spine 22:288-293, 2015

7. Buxton M, O'Hanlon M, Rushby J, Pekurinen M, Sintonen H, Bjork S, et al: EuroQol-a new facility for the measurement of health-related quality of life. Health Policy 16:199-208, 1990

8. Carreon LY, Glassman SD, Kantamneni NR, Mugavin MO, Djurasovic M: Clinical outcomes after posterolateral lumbar fusion in workers' compensation patients: a case-control study. Spine (Phila Pa 1976) 35:1812-1817, 2010

9. Fairbank JC, Pynsent PB: The Oswestry Disability Index. Spine (Phila Pa 1976) 25:2940-2952, 2000

10. Franklin GM, Haug J, Heyer NJ, McKeefrey SP, Picciano JF: Outcome of lumbar fusion in Washington State workers' compensation. Spine (Phila Pa 1976) 19:1897-1904, 1994

11. Ghogawala Z, Shaffrey CI, Asher AL, Heary RF, Logvinenko T, Malhotra NR, et al: The efficacy of lumbar discectomy and single-level fusion for spondylolisthesis: results from the NeuroPoint-SD registry: clinical article. J Neurosurg Spine 19:555-563, 2013

12. Gulati S, Nordseth T, Nerland US, Gulati M, Weber C, Giannadakis C, et al: Does daily tobacco smoking affect outcomes after microdecompression for degenerative central lumbar spinal stenosis? - A multicenter observational registry-based study. Acta Neurochir (Wien) 157:1157-1164, 2015

13. Guo Y, Logan HL, Marks JG, Shenkman EA: The relationships among individual and regional smoking, socioeconomic status, and oral and pharyngeal cancer survival: a mediation analysis. Cancer Med 4:1612-1619, 2015

14. Harrell FE Jr, Lee KL, Califf RM, Pryor DB, Rosati RA: Regression modelling strategies for improved prognostic prediction. Stat Med 3:143-152, 1984

15. Harrer SW, Carlson WO: Spinal health and smoking. S D Med 62:309, 311-303, 2009

16. Harris PA, Taylor R, Thielke R, Payne J, Gonzalez N, Conde JG: Research electronic data capture (REDCap) - a metadata-driven methodology and workflow process for providing translational research informatics support. J Biomed Inform 42:377-381, 2009

17. Hilibrand AS, Fye MA, Emery SE, Palumbo MA, Bohlman $\mathrm{HH}$ : Impact of smoking on the outcome of anterior cervical arthrodesis with interbody or strut-grafting. J Bone Joint Surg Am 83-A:668-673, 2001

18. Kusin DJ, Ahn UM, Ahn NU: The effect of smoking on spinal cord healing following surgical treatment of cervical myelopathy. Spine (Phila Pa 1976) 40:1391-1396, 2015

19. Laaksonen M, Talala K, Martelin T, Rahkonen O, Roos E, Helakorpi S, et al: Health behaviours as explanations for educational level differences in cardiovascular and all-cause mortality: a follow-up of 60000 men and women over 23 years. Eur J Public Health 18:38-43, 2008

20. Langley GB, Sheppeard H: The visual analogue scale: its use in pain measurement. Rheumatol Int 5:145-148, 1985

21. Lau D, Chou D, Ziewacz JE, Mummaneni PV: The effects of smoking on perioperative outcomes and pseudarthrosis following anterior cervical corpectomy: clinical article. J Neurosurg Spine 21:547-558, 2014

22. Lehto MU, Honkanen P: Factors influencing the outcome of operative treatment for lumbar spinal stenosis. Acta Neurochir (Wien) 137:25-28, 1995

23. Luszczyk M, Smith JS, Fischgrund JS, Ludwig SC, Sasso RC, Shaffrey CI, et al: Does smoking have an impact on fusion rate in single-level anterior cervical discectomy and fusion with allograft and rigid plate fixation? Clinical article. J Neurosurg Spine 19:527-531, 2013

24. McGirt MJ, Parker SL, Asher AL, Norvell D, Sherry N, Devin CJ: Role of prospective registries in defining the value and effectiveness of spine care. Spine (Phila Pa 1976) 39 (22 Suppl 1):S117-S128, 2014

25. McGirt MJ, Sivaganesan A, Asher AL, Devin CJ: Prediction model for outcome after low-back surgery: individualized likelihood of complication, hospital readmission, return to work, and 12-month improvement in functional disability. Neurosurg Focus 39(6):E13, 2015

26. Møller AM, Pedersen T, Villebro N, Munksgaard A: Effect of smoking on early complications after elective orthopaedic surgery. J Bone Joint Surg Br 85:178-181, 2003

27. Moyses RA, López RV, Cury PM, Siqueira SA, Curioni OA, Gois Filho JF, et al: Significant differences in demographic, clinical, and pathological features in relation to smoking and alcohol consumption among 1,633 head and neck cancer patients. Clinics (Sao Paulo) 68:738-744, 2013

28. Nerland US, Jakola AS, Giannadakis C, Solheim O, Weber C, Nygaard OP, et al: The risk of getting worse: predictors of deterioration after decompressive surgery for lumbar spinal 
stenosis: a multicenter observational study. World Neurosurg 84:1095-1102, 2015

29. Olson PR, Lurie JD, Frymoyer J, Walsh T, Zhao W, Morgan TS, et al: Lumbar disc herniation in the Spine Patient Outcomes Research Trial: does educational attainment impact outcome? Spine (Phila Pa 1976) 36:2324-2332, 2011

30. Orhurhu VJ, Pittelkow TP, Hooten WM: Prevalence of smoking in adults with chronic pain. Tob Induc Dis 13:17, 2015

31. Pearson A, Lurie J, Tosteson T, Zhao W, Abdu W, Weinstein JN: Who should have surgery for spinal stenosis? Treatment effect predictors in SPORT. Spine (Phila Pa 1976) 37:17911802,2012

32. Sandén B, Försth P, Michaëlsson K: Smokers show less improvement than nonsmokers two years after surgery for lumbar spinal stenosis: a study of 4555 patients from the Swedish spine register. Spine (Phila Pa 1976) 36:1059-1064, 2011

33. Seicean A, Seicean S, Alan N, Schiltz NK, Rosenbaum BP, Jones PK, et al: Effect of smoking on the perioperative outcomes of patients who undergo elective spine surgery. Spine (Phila Pa 1976) 38:1294-1302, 2013

34. Vasquez RA, Chotai S, Wick JB, Stonko DP, Cheng JS, Bydon M, et al: The profile of a smoker and its impact on outcomes after cervical spine surgery. Neurosurgery 63 (Suppl 1):96-101, 2016

\section{Disclosures}

Dr. Devin reports being a consultant to Pacira and has performed defense expert witness work. Dr. Mummaneni reports being a consultant to DePuy Spine; having direct stock ownership in Spinicity/ISD; receiving honoraria from AOSpine; and receiving royalties from DePuy Spine, Thieme Publishing, and Springer
Publishing. Dr. Glassman reports being an employee of Norton Healthcare; a patent holder for Medtronic; a consultant for Medtronic; a past president of the Scoliosis Research Society; and receiving funds from NuVasive directly to his database company (no funds paid directly to an individual or an individual's institution).

\section{Author Contributions}

Conception and design: Asher, Devin, Chotai, Archer, McGirt, Bydon. Acquisition of data: Chotai, Nian, Harrell. Analysis and interpretation of data: Asher, Devin, McCutcheon, Chotai, Nian, Harrell, Bydon. Drafting the article: Devin, McCutcheon, Chotai. Critically revising the article: Asher, Devin, McCutcheon, Chotai, Archer, McGirt, Mummaneni, Shaffrey, Foley, Glassman, Bydon. Reviewed submitted version of manuscript: Asher, Devin, McCutcheon, Chotai, Archer, McGirt, Mummaneni, Shaffrey, Foley, Bydon. Approved the final version of the manuscript on behalf of all authors: Asher. Statistical analysis: Nian, Harrell. Administrative/technical/material support: Chotai, Nian. Study supervision: Asher, Devin, Harrell, Mummaneni, Bydon.

\section{Supplemental Information Online-Only Content}

Supplemental material is available with the online version of the article.

Supplemental Figs. 1-3. https://thejns.org/doi/suppl/10.3171/ 2017.4.SPINE16984.

\section{Correspondence}

Anthony L. Asher, Department of Neurological Surgery, Carolina Neurosurgery and Spine Associates, 225 Baldwin Rd., Charlotte, NC 28204. email: tony.asher@cnsa.com. 